\title{
Endophthalmitis after Cataract Surgery in Korea: A Nationwide Study Evaluating Incidence and Risk Factors in a Korean Population
}

\author{
Soo Han Kim ${ }^{1}$, Min Heui Yu ${ }^{2}$, Joung Hyuck Lee ${ }^{1}$, Sun Woong Kim ${ }^{1}$, and Sang Hoon Rah ${ }^{1}$ \\ ${ }^{1}$ Departments of Ophthalmology and ${ }^{2}$ Biostatistics, Yonsei University Wonju College of Medicine, Wonju, Korea.
}

\begin{abstract}
Purpose: To assess the nationwide rate of acute postoperative endophthalmitis (APE) after cataract extraction in Korea and to evaluate potential risk factors thereof.

Materials and Methods: Nationwide insurance claims data from July 2014 to June 2017 were reviewed. All patients with phacoemulsification or extracapsular/intracapsular cataract extraction were included. Exclusion criteria were combined glaucoma surgery or total vitrectomy or when the patient had a history of intraocular foreign body.

Results: In total, 1505103 cases (982203 patients) were included. APE developed in 953 cases (938 patients) with an overall incidence of $0.063 \%$. After adjusting for possible confounding factors, male sex [odds ratio (OR) 1.42; 95\% confidence interval (CI) $1.25-1.61 ; p<0.001$ ], primary clinical setting, operations performed in non-major cities, usage of sutures (OR 2.82; 95\% CI 2.133.74; $p<0.001$ ), anterior vitrectomy (OR 8.71; 95\% CI 6.71-11.32; $p<0.001$ ), aphakic cataract surgery (OR 1.52; 95\% CI 1.03-2.22; $p=$ 0.033 ), hypertension (OR 1.40; 95\% CI 1.18-1.66; $p<0.001$ ), diabetes (OR 1.59; 95\% CI 1.31-1.93; $p<0.001$ ), and chronic renal failure (OR 1.28; 95\% CI 1.01-1.62; $p=0.039$ ) were found to be related to APE development.

Conclusion: The incidence of APE after cataract extraction was consistent with reports from other studies. Additional research is needed to determine the relationship of newly found risk factors, such as hypertension, primary clinical setting, chronic renal failure, and usage of suturing, with APE development.
\end{abstract}

Key Words: Cataract, endophthalmitis, Korea, phacoemulsification

\section{INTRODUCTION}

Cataract surgery is one of the most commonly performed surgeries worldwide. Due to advancement in surgical techniques and materials, cataract surgery has become faster and safer. ${ }^{1}$ However, complications of posterior capsular tear, loss of endothelial cells, corneal stromal burn, postoperative endophthalmitis, and even retinal detachment still occur., ${ }^{2,3}$

\footnotetext{
Received: November 16, 2018 Revised: February 1, 2019

Accepted: March 6, 2019

Corresponding author: Sang Hoon Rah, MD, PhD, Department of Ophthalmology, Wonju Severance Christian Hospital, 20 IIsan-ro, Wonju 26426, Korea. Tel: 82-33-741-0633, Fax: 82-33-741-1144, E-mail: shrah@yonsei.ac.kr

-The authors have no potential conflicts of interest to disclose.

(C) Copyright: Yonsei University College of Medicine 2019

This is an Open Access article distributed under the terms of the Creative Commons Attribution Non-Commercial License (https://creativecommons.org/licenses/ by-nc/4.0) which permits unrestricted non-commercial use, distribution, and reproduction in any medium, provided the original work is properly cited.
}

Acute postoperative endophthalmitis (APE) is a rare, but devastating complication of cataract surgery. Its incidence is reported to be approximately $0.023 \%$ to $0.26 \%$, depending on the report. ${ }^{4-8}$ Commonly known risk factors for APE include older age, diabetes, posterior capsular tear and, although controversial, silicone intraocular lenses (IOLs), among others. ${ }^{7-9}$ To prevent APE, aseptic procedure, intracameral injection of cefuroxime, and intracameral moxifloxacin injection have been shown to be effective in several studies. ${ }^{8,10-12}$

There are many studies on APE, most of which have been conducted at several institutions, in the past, or from Western nationwide data. ${ }^{4,7,12,13}$ The purpose of the present study was to evaluate the nationwide incidence of APE after cataract surgery in Koreans and to investigate risk factors related to the development of APE. 


\section{MATERIALS AND METHODS}

National Health Insurance (NIH) is a universal health insurance system in South Korea. ${ }^{14}$ All Korean citizens are required to be registered with the NIH regardless of income, employment status, or marriage status. ${ }^{15}$ Health Insurance Review and Assessment Service (HIRA) is a government organization under the NIH that is responsible for reviewing medical bills, as well as conducting quality assessment of health care services. ${ }^{14}$ When a healthcare provider offers a medical service, they file a claim to the HIRA to obtain repayment for the service that they provided to patients. ${ }^{14}$ After July 2013, cataract surgery in Korea was assigned to the Diagnosis Related Group payment system; therefore, all cataract surgery claims must be filed to the HIRA for reimbursement and quality assessment. The HIRA's database is not open source. The data used in this study are available solely to the authors; researchers can apply to the HIRA after obtaining approval from the institutional review board of the institution. The Institutional Review Board of the Wonju Severance Christian Hospital approved this study (IRB number: CR317339), which adhered to the tenets of the Declaration of Helsinki.

We selected patients who had a cataract surgery recorded in the HIRA database between July 1, 2014, and June 31, 2017. For each patient, cataract surgery was identified by the code S5119 (phacoemulsification) or S5111 [intracapsular cataract extraction (ICCE)/extracapsular cataract extraction (ECCE)]. We also reviewed procedures based on IOL placement. The code for IOL included S5117 (IOL primary) and S5116 (IOL secondary). Patients who had a history of intraocular foreign body (H446, H447) were excluded. Patients with combined glaucoma surgery (S5043, S5047, S5049) or total vitrectomy (S5122, S5121) were also excluded. APE was defined when endophthalmitis criteria were found within 42 days following the date of cataract surgery. Endophthalmitis was defined as 1) diagnoses of endophthalmitis (H440, H441, H451, H59802) and treatment of vitrectomy (S5122, S5121); 2) diagnoses of endophthalmitis and antibiotic injection; or 3) antibiotic injection without diagnoses of endophthalmitis. The criteria for the use of antibiotics were based on injections of either vancomycin, amikacin, ceftriaxone, ceftazidime, or amphotericin B.

Posterior capsular tear was defined when anterior vitrectomy was performed. Usage of sutures was defined when a 10/0 nylon suture was used during surgery. Hypertension and diabetes were defined when diagnosis codes for hypertension (I10) and diabetes (E08-13) with antihypertensive medication or diabetes medications were found. Other medical conditions, such as heart failure, hepatic failure, dementia, stroke, etc., were included when a patient diagnosis code was present regardless of the medications.

Clinical setting was divided as primary, secondary, and tertiary hospitals. Because the information is protected, patient addresses could not be determined; thus, the address was eval- uated based on the address of the hospital where the operation was performed. The address was divided into Seoul, metropolitan, and other areas. Income levels were classified according to whether the patients were covered under medical insurance or medical care, government expenditures, or patriots and veterans' affairs.

Statistical analysis was performed using independent twosample t-test and chi-square (or Fisher's exact) test. For continuous variables, the data are expressed as the mean \pm standard deviation. For categorical variables, the data are expressed as counts and percentage. To assess potential risk factors for APE after cataract surgery, separate univariable logistic regression models were created with each covariate as an independent predictor and APE as the outcome. Covariates with $p<0.1$ in the univariable models were included in one multivariable model to assess for multivariable predictors of APE after cataract surgery. Results were reported as odds ratio (OR) and 95\% confidence intervals (CI). All statistical analyses were performed with SAS Enterprise Guide 6.1 (SAS Institute Inc., Cary, NC, USA). All the tests were 2 -sided, and $p$ values $<0.05$ were considered significant.

\section{RESULTS}

A flow diagram of the inclusion and exclusion of participants is provided in Fig. 1. A total of 1048164 patients were enrolled from July 2014 to June 2017. We excluded 198 patients due to intraocular foreign body history and 62412 patients with combined glaucoma and total vitrectomy surgery. Additionally, 3351 patients had IOL implantation alone. Finally, 1505103 cases of cataract surgery (982203 patients) were included in this study of APE development after cataract surgery.

In 953 eyes of 938 patients, APE developed with an overall

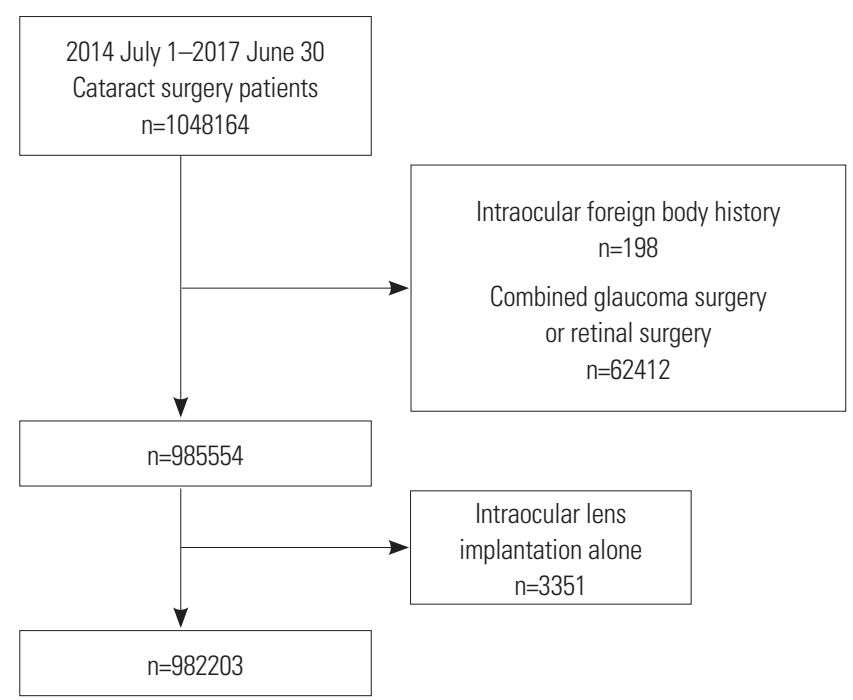

Fig. 1. Flowchart for selection of study patients from the Health Insurance Review and Assessment Service from July 2014 to June 2017. 
incidence rate of $0.063 \%$. The annual incidences of APE were $0.067 \%$ in 2014 (July 2014-June 2015), 0.064\% in 2015 (July 2015-June 2016), and 0.058\% in 2016 (July 2016-June 2017). Demographic factors of cataract patients are shown in Table 1. The mean age at which patients underwent cataract surgery was $69.10 \pm 10.41$ years. Patients with APE were more likely to be male $(p<0.001)$, have undergone surgery at a lower clinical setting ( $p=0.001)$, live in a rural region ( $p=0.002)$, have low income status $(p<0.001)$, and have a medical history of hypertension $(p<0.001)$, diabetes $(p<0.001)$, heart disease $(p=0.038)$, hepatic disease (including chronic hepatitis) $(p=0.040)$, renal failure $(p<0.001)$, or dementia $(p=0.006)$.

Results of case-wise data examination and univariable regression analysis are shown in Table 2 . With respect to surgical aspects, patients with APE received more sutures $(p<0.001)$ and anterior vitrectomy $(p<0.001)$.

Results of case-wise multivariable regression analysis are shown in Fig. 2. After adjusting for possible confounding factors, male sex (OR 1.42; 95\% CI 1.25-1.61; $p<0.001$ ), primary clinical setting, operations performed in non-major cities, usage of sutures (OR 2.82; 95\%CI 2.13-3.74; $p<0.001$ ), anterior vitrectomy (OR 8.71; 95\% CI 6.71-11.32; $p<0.001$ ), aphakic cataract surgery (OR 1.52; 95\% CI 1.03-2.22; $p=0.033$ ), hypertension (OR 1.40; 95\% CI 1.18-1.66; $p<0.001$ ), diabetes (OR 1.59;
95\% CI 1.31-1.93; $p<0.001$ ), and chronic renal failure (OR 1.28; 95\%CI 1.01-1.62; $p=0.039$ ) were found to be associated with APE development.

There were 3351 eyes from 3351 patients with IOL implantation without phacoemulsification or ECCE/ICCE. Primary IOL implant was performed in 690 eyes (690 patients), and secondary IOL implant was performed in 2661 eyes (2661 patients). None of the patients with IOL implantation only developed APE.

\section{DISCUSSION}

Demand for cataract surgery is increasing due to aging populations, and complications after cataract surgery are a growing concern. Therefore, safer, faster, and cheaper cataract surgery that avoids possible risk factors is crucial. Also, in terms of quality management, continuous monitoring of complications of cataract surgery is needed. The overall APE rate in Korea from July 2012 to Jun 2014 was $0.063 \%$, which is consistent with previous reports.

Preoperative immune status is important in APE development. ${ }^{16,17}$ In the present study, hypertension, diabetes, and chronic renal failure were associated with APE development.

Table 1. Demographic and Clinical Characteristics of the Study Patients

\begin{tabular}{|c|c|c|c|c|}
\hline \multirow{2}{*}{ Variable } & \multirow{2}{*}{ Total $(n=982203)$} & \multicolumn{2}{|c|}{ APE development } & \multirow{2}{*}{$p$ value } \\
\hline & & No $(n=981265)$ & Yes $(n=938)$ & \\
\hline Age (yr) & & & & 0.412 \\
\hline$<85$ & $36390(3.70)$ & 36360 (99.92) & $30(0.08)$ & \\
\hline$\geq 85$ & 945812 (96.30) & 944905 (99.90) & $907(0.10)$ & \\
\hline Male sex & 418130 (42.57) & 417655 (99.89) & $475(0.11)$ & $<0.001$ \\
\hline Clinical setting & & & & 0.001 \\
\hline 1 & $69249(7.05)$ & $69153(99.86)$ & $96(0.14)$ & \\
\hline 2 & $156653(15.95)$ & 156507 (99.91) & $146(0.09)$ & \\
\hline 3 & $756300(77.00)$ & 755605 (99.91) & $695(0.09)$ & \\
\hline Residence & & & & 0.002 \\
\hline Seoul & $223243(22.74)$ & 223070 (99.92) & $173(0.08)$ & \\
\hline Metropolitan city & $280336(28.56)$ & 280077 (99.91) & $259(0.09)$ & \\
\hline Others & $477993(48.70)$ & 477488 (99.89) & $505(0.11)$ & \\
\hline Income & & & & $<0.001$ \\
\hline Health insurance & 912891 (92.94) & 912062 (99.91) & $829(0.09)$ & \\
\hline Government expenditure & $69311(7.06)$ & 69203 (99.84) & $108(0.16)$ & \\
\hline HTN & 157902 (16.08) & $157656(99.84)$ & $246(0.16)$ & $<0.001$ \\
\hline DM & $82672(8.42)$ & 82514 (99.81) & $158(0.19)$ & $<0.001$ \\
\hline Heart failure & $92662(9.43)$ & 92555 (99.88) & $107(0.12)$ & 0.038 \\
\hline Hepatic failure/chronic hepatitis & $164159(16.71)$ & 163979 (99.89) & $180(0.11)$ & 0.040 \\
\hline Renal failure & $50308(5.12)$ & 50224 (99.83) & $84(0.17)$ & $<0.001$ \\
\hline Dementia & $94544(9.63)$ & 94429 (99.88) & $115(0.12)$ & 0.006 \\
\hline Atopic dermatitis & $63790(6.49)$ & 63719 (99.89) & $71(0.11)$ & 0.178 \\
\hline Allergic rhinitis & 762265 (77.61) & 761551 (99.91) & $714(0.09)$ & 0.301 \\
\hline
\end{tabular}

APE, acute postoperative endophthalmitis; HTN, hypertension; DM, diabetes mellitus.

Variables are presented as a number of patients (\%). 
Table 2. Cataract Cases and Univariable Regression Analysis with APE Development

\begin{tabular}{|c|c|c|c|c|c|}
\hline \multirow{2}{*}{ Variable } & \multicolumn{3}{|c|}{ APE development in cataract surgery } & \multicolumn{2}{|c|}{ Univariable analysis } \\
\hline & No $(n=1506057)$ & Yes (n=953) & $p$ value & OR (95\% Cl) & $p$ value \\
\hline Age (yr) & & & 0.453 & & \\
\hline$<85$ & 54303 (99.94) & $30(0.06)$ & & 1 (reference) & \\
\hline$\geq 85$ & 1450800 (99.94) & $921(0.06)$ & & $1.15(0.80-1.65)$ & 0.454 \\
\hline Sex & & & $<0.001$ & & \\
\hline Female & $889063(99.95)$ & $468(0.05)$ & & 1 (reference) & \\
\hline Male & 616040 (99.92) & $483(0.08)$ & & $1.49(1.31-1.69)$ & $<0.001$ \\
\hline Clinical setting & & & $<0.001$ & & \\
\hline 1 & 94671 (99.90) & $98(0.10)$ & & 1 (reference) & \\
\hline 2 & 240782 (99.93) & $157(0.07)$ & & $0.63(0.49-0.81)$ & 0.054 \\
\hline 3 & 1169650 (99.94) & $696(0.06)$ & & $0.58(0.47-0.71)$ & $<0.001$ \\
\hline Residence & & & 0.002 & & \\
\hline Seoul & 335708 (99.95) & $178(0.05)$ & & 1 (reference) & \\
\hline Metropolitan city & 436872 (99.94) & $260(0.06)$ & & $1.12(0.93-1.36)$ & 0.743 \\
\hline Others & 730794 (99.93) & $513(0.07)$ & & $1.32(1.12-1.57)$ & 0.001 \\
\hline Income & & & $<0.001$ & & \\
\hline Health care & 1394596 (99.94) & $838(0.06)$ & & 1 (reference) & \\
\hline Government expenditure & 110507 (99.90) & $113(0.10)$ & & $1.70(1.40-2.07)$ & $<0.001$ \\
\hline Surgery type & & & 0.356 & & \\
\hline Phacoemulsification & 1383867 (99.94) & $884(0.06)$ & & 1 (reference) & \\
\hline ECCE & 121237 (99.94) & $69(0.06)$ & & $0.89(0.70-1.14)$ & 0.356 \\
\hline Using suture (ref. no) & 47338 (99.79) & $100(0.21)$ & $<0.001$ & $3.62(2.94-4.45)$ & $<0.001$ \\
\hline Anterior vitrectomy (ref. no) & 9753 (99.32) & $67(0.68)$ & $<0.001$ & 11.61 (9.05-14.88) & $<0.001$ \\
\hline IOL implantation & & & 0.011 & & \\
\hline Primary & 1468056 (99.94) & $916(0.06)$ & & 1 (reference) & \\
\hline Secondary & 9185 (99.92) & $7(0.08)$ & & $1.22(0.58-2.57)$ & 0.852 \\
\hline None & 27863 (99.89) & $30(0.11)$ & & $1.73(1.20-2.48)$ & 0.091 \\
\hline Both eyes (ref. no) & 21886 (99.88) & $26(0.12)$ & 0.001 & $1.90(1.29-2.81)$ & 0.001 \\
\hline Intraoperative cefuroxime & 1612 (99.88) & $2(0.12)$ & $0.649^{*}$ & $1.38(0.34-5.53)$ & 0.649 \\
\hline HTN (ref. no) & 244435 (99.90) & $249(0.10)$ & $<0.001$ & $1.83(1.58-2.11)$ & $<0.001$ \\
\hline DM (ref. no) & 127176 (99.87) & $161(0.13)$ & $<0.001$ & $2.21(1.86-2.62)$ & $<0.001$ \\
\hline Heart failure (ref. no) & 143219 (99.93) & $107(0.07)$ & 0.068 & $1.21(0.99-1.48)$ & 0.068 \\
\hline Hepatic failure/chronic hepatitis (ref. no) & $252636(99.93)$ & $181(0.07)$ & 0.064 & $1.17(0.99-1.37)$ & 0.064 \\
\hline Renal failure (ref. no) & 76586 (99.89) & $87(0.11)$ & $<0.001$ & $1.88(1.51-2.34)$ & $<0.001$ \\
\hline Dementia (ref. no) & $145595(99.92)$ & $116(0.08)$ & 0.009 & $1.30(1.07-1.58)$ & 0.009 \\
\hline Atopic dermatitis (ref. no) & 98895 (99.93) & $72(0.07)$ & 0.213 & $1.17(0.92-1.48)$ & 0.214 \\
\hline Allergic rhinitis (ref. no) & 1173560 (99.94) & $725(0.06)$ & 0.197 & $0.91(0.78-1.05)$ & 0.197 \\
\hline
\end{tabular}

APE, acute postoperative endophthalmitis; ECCE, extracapsular cataract extraction; IOL, intraocular lens; HTN, hypertension; DM, diabetes mellitus; OR, odds ratio; $\mathrm{Cl}$, confidence interval; ref, reference.

Variables are presented as a number of cataract case (\%).

*Fisher's exact test.

Diabetes is a well-known risk factor for APE. ${ }^{7-9}$ However, studies reporting the relationship between hypertension and APE development were difficult to find. Hypertension could be a confounding factor for APE development; however, there is a possibility that hypertension itself could be a risk factor for APE, as an association between hypertension and immune system dysfunction has been shown in several studies. ${ }^{18,19}$ Further studies are needed to determine whether hypertension is a direct cause of endophthalmitis. Chronic renal failure also affects immune function and renders the patient prone to various infections, such as APE. ${ }^{20}$ However, the authors were unable to find other large studies reporting associations between APE and chronic renal failure.

In the present study, clinical settings and region of surgery were also associated with APE development. Secondary and tertiary referral hospitals had lower incidences of APE development. Interestingly only 94671 (6.3\%) of all cataract surgeries was performed at primary clinics. According to the HIRA, 


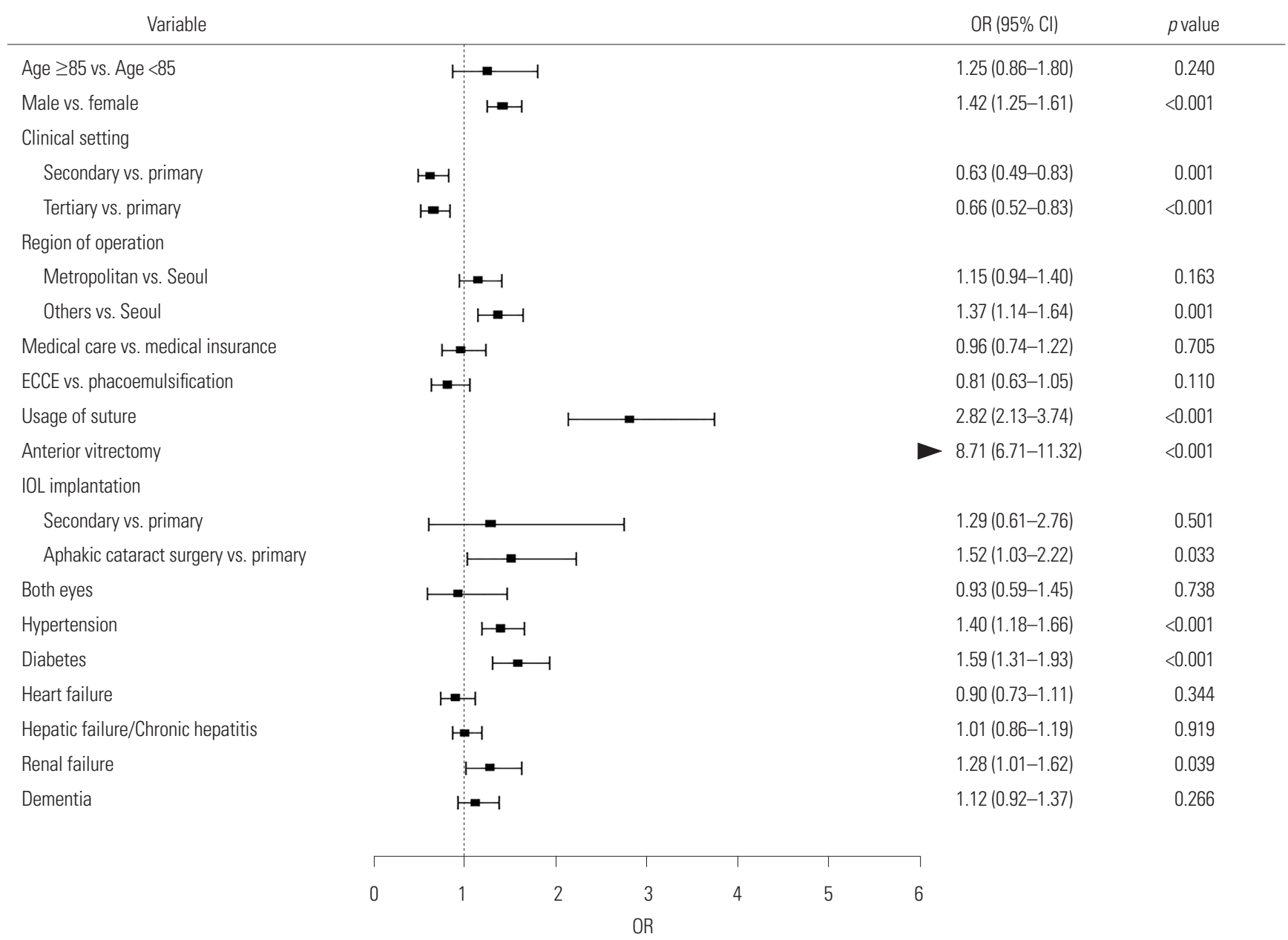

Fig. 2. Forest plot of ORs and 95\% Cls for risk factors for acute postoperative endophthalmitis development. ECCE, extracapsular cataract extraction; $\mathrm{IOL}$, intraocular lens; $\mathrm{OR}$, odds ratio; $\mathrm{Cl}$, confidence interval.

there are 1561 ophthalmology clinics, 78 secondary hospitals, and 173 tertiary referral centers registered. ${ }^{21}$ The authors cautiously suspect that, since only $6.3 \%$ of cataract surgeries are performed in private clinics, which account for more than $85 \%$ of the total number of ophthalmologic hospitals, this shows that cataract surgery is not performed frequently, so it may be difficult to maintain sterilization of facilities and instruments. Further study and education should be performed regarding this matter. Patients who received cataract surgery in non-major cities had higher APE development rates. This suggests that environmental factors also affect APE development.

Whether ECCE or phacoemulsification poses a higher risk of APE is controversial. Theoretically, ECCE would pose a higher risk due to the larger surgical incision and inflow of fluid from the ocular surface during surgery. While some reports suggest increased risk in ECCE, ${ }^{22}$ Wong and $\mathrm{Chee}^{4}$ reported that phacoemulsification had a three-fold higher risk of developing APE, although the reason was unclear. In the present study, ECCE exhibited a reduced risk, although the difference was not statistically significant (OR 0.81; $p=0.110$ ).

Herein, we found anterior vitrectomy to be strongly associ- ated with APE development (OR 8.71; $p<0.001$ ). Posterior capsular tear is a common intraoperative complication during cataract surgery. ${ }^{23}$ Many reports show an increased risk of developing APE in patients with posterior capsular tear. ${ }^{7}$ When the posterior capsule is ruptured, a longer duration of surgery is needed, and delayed bacterial elimination from the vitreous is assumed to be a reason for increased APE development. ${ }^{4}$ Anterior vitrectomy was the most important risk factor for the occurrence of endophthalmitis, and close observation is needed both during and after surgery for possible APE development.

In this study, leaving the patient aphakic was associated with higher APE risk (OR 1.52; $p=0.033$ ). Aphakia after cataract surgery is usually unplanned and primarily caused by a surgical complication: ${ }^{24}$ the authors suspect it is mainly from intraoperative complications. In the prevention thereof, intracameral cefuroxime was found to be effective in several studies. ${ }^{8,10-11}$ However, the prophylactic effect of cefuroxime was not statistically significant in this study.

The most interesting finding in the present study was that usage of sutures increased the risk of developing APE. The incidence of APE had been on a continuous decrease until 1992, 
the year in which the self-sealing clear corneal incision was introduced. After 1992, an increased incidence of APE was described. ${ }^{25,26}$ Widespread use of clear corneal incisions was thought to be one of the reasons for increased APE development. ${ }^{26}$ While clear corneal incision offers a shorter procedure time, less astigmatism, and faster visual recovery, compared with a scleral tunnel procedure, ${ }^{25}$ wound integrity and fluid influx from self-sealing clear corneal incisions have been issues for a long time..$^{27,28}$ Also, whether suturing of the corneal wound in cataract surgery improves wound integrity has been debated. ${ }^{29,30}$ The role of sutures in postoperative endophthalmitis is controversial. Lee, et al. ${ }^{31}$ reported suture-related delayed postoperative endophthalmitis. However, Thomas, et al. ${ }^{32}$ suggested that suturing decreased the rate of APE. In the present study, use of sutures was associated with increased APE even after correction for ECCE and ICCE in multivariable logistic regression. Using sutures during surgery could mean several things. Sutures could be used to improve wound stability in non-complicated surgery or it could also be related to wider incisions, complications, such as corneal stromal burn, prolonged and excessive manipulations, and sutured scleral incisions, etc., which could also have an effect on APE development. Although the suture itself could be a focus for infections, concluding that suturing is related to APE will require further evaluation.

There are several limitations to this study. First, error or loss in coding is possible. ${ }^{33}$ If complications, such as dropped nucleus, occurred and a patient received a total vitrectomy, the patient is no longer included in the diagnosis-related groups. These patients were impossible to distinguish from planned phaco-vitrectomy. Therefore, some patients may have been overly excluded in the present study. Also, since hospitals claim a reimbursement from the HIRA after the procedure, loss to claim used materials could be possible. In addition, the database does not clarify the route of antibiotics administration nor laterality of surgery, leading to overestimation of APE development. Second, inflammatory disease, such as toxic anterior segment syndrome, could be coded as endophthalmitis, which could be confused as APE. Fifteen patients were suspected to have bilateral APE. Although it is not impossible to develop bilateral APE, authors suspect that if APE occurred in the first operation, it is likely that the surgeon may have over treated inflammatory reactions after fellow eye surgery. Therefore, there is a possibility that the incidence of APE is overestimated. Third, the period of observation time was short. The authors reviewed only 3 years of cataract surgeries due to size limitations of the HIRA database, and trends in APE development could not be evaluated. Fourth, information regarding the type and placement of incision was not available, and clear corneal incision and temporal placement are considered risk factors for developing APE. ${ }^{26}$ Fifth, the IOL material is unknown, since previous studies have suggested that certain types of IOL may be implicated in APE development. ${ }^{34}$ However, the

material of the IOL could not be identified in this study. Another limitation is that this study did not clearly identify the residence of the patients. If the patient is operated outside their area of residence, there may be an error in the evaluation. Despite these limitations, this study is the first nationwide evaluation of APE development in Korea and has the advantage of evaluating variables that were not identified in other studies.

The overall rate of APE was $\mathbf{0 . 0 6 3 \%}$ in South Korea form July 2014 to June 2017. Preoperative risk factors for APE were male sex, hypertension, diabetes, and chronic renal failure. Intraoperative risk factors were usage of sutures, anterior vitrectomy, and aphakic cataract surgeries. Operations performed in non-major cities in a primary clinical setting were also associated with increased development of APE. Additional research is needed to determine the relationship of newly found risk factors, such as hypertension, primary clinical setting, chronic renal failure, and usage of sutures, with APE development. No APE developed after IOL implantation only without cataract extractions.

\section{AUTHOR CONTRIBUTIONS}

Conceptualization: Soo Han Kim, Joung Hyuck Lee, Sun Woong Kim, Sang Hoon Rah. Data curation: Soo Han Kim, Min Heui Yu. Formal analysis: Min Heui Yu. Investigation: Soo Han Kim, Sun Woong Kim. Methodology: Soo Han Kim. Project administration: Joung Hyuck Lee, Sang Hoon Rah. Resources: Sun Woong Kim. Software: Min Heui Yu. Supervision: Sang Hoon Rah. Validation: Min Heui Yu. Visualization: Min Heui Yu. Writing_original draft: Soo Han Kim. Writingreview \& editing: Joung Hyuck Lee, Sun Woong Kim, Sang Hoon Rah.

\section{ORCID iDs}

Soo Han Kim Min Heui Yu Joung Hyuck Lee Sun Woong Kim Sang Hoon Rah

\section{REFERENCES}

1. Weikert MP. Update on bimanual microincisional cataract surgery. Curr Opin Ophthalmol 2006;17:62-7.

2. Yorston D. Cataract complications. Community Eye Health 2008; 21:1-3.

3. Sugar A, Schertzer RM. Clinical course of phacoemulsification wound burns. J Cataract Refract Surg 1999;25:688-92.

4. Wong TY, Chee SP. The epidemiology of acute endophthalmitis after cataract surgery in an Asian population. Ophthalmology 2004;111: 699-705.

5. Greenberg PB, Tseng VL, Wu WC, Liu J, Jiang L, Chen CK, et al. Prevalence and predictors of ocular complications associated with cataract surgery in United States veterans. Ophthalmology 2011;118:507-14.

6. West ES, Behrens A, McDonnell PJ, Tielsch JM, Schein OD. The incidence of endophthalmitis after cataract surgery among the U.S. Medicare population increased between 1994 and 2001. Ophthal- 
mology 2005;112:1388-94.

7. Creuzot-Garcher C, Benzenine E, Mariet AS, de Lazzer A, Chiquet $\mathrm{C}$, Bron AM, et al. Incidence of acute postoperative endophthalmitis after cataract surgery: a nationwide study in France from 2005 to 2014. Ophthalmology 2016;123:1414-20.

8. Jabbarvand M, Hashemian H, Khodaparast M, Jouhari M, Tabatabaei A, Rezaei S. Endophthalmitis occurring after cataract surgery: outcomes of more than 480000 cataract surgeries, epidemiologic features, and risk factors. Ophthalmology 2016;123:295-301.

9. Hashemian H, Mirshahi R, Khodaparast M, Jabbarvand M. Postcataract surgery endophthalmitis: brief literature review. J Curr Ophthalmol 2016;28:101-5.

10. Montan PG, Wejde G, Koranyi G, Rylander M. Prophylactic intracameral cefuroxime. Efficacy in preventing endophthalmitis after cataract surgery. J Cataract Refract Surg 2002;28:977-81.

11. García-Sáenz MC, Arias-Puente A, Rodríguez-Caravaca G, Banuelos JB. Effectiveness of intracameral cefuroxime in preventing endophthalmitis after cataract surgery: ten-year comparative study. J Cataract Refract Surg 2010;36:203-7.

12. Haripriya A, Chang DF, Namburar S, Smita A, Ravindran RD. Efficacy of intracameral moxifloxacin endophthalmitis prophylaxis at Aravind Eye Hospital. Ophthalmology 2016;123:302-8.

13. Lundström M, Wejde G, Stenevi U, Thorburn W, Montan P. Endophthalmitis after cataract surgery: a nationwide prospective study evaluating incidence in relation to incision type and location. Ophthalmology 2007;114:866-70.

14. Kim L, Kim JA, Kim S. A guide for the utilization of Health Insurance Review and Assessment Service National Patient Samples. Epidemiol Health 2014;36:e2014008.

15. Jang MJ, Bang SM, Oh D. Incidence of venous thromboembolism in Korea: from the Health Insurance Review and Assessment Service database. J Thromb Haemost 2011;9:85-91.

16. Aaberg TM Jr, Flynn HW Jr, Schiffman J, Newton J. Nosocomial acute-onset postoperative endophthalmitis survey. A 10-year review of incidence and outcomes. Ophthalmology 1998;105:1004-10.

17. Miller JJ, Scott IU, Flynn HW Jr, Smiddy WE, Newton J, Miller D. Acute-onset endophthalmitis after cataract surgery (2000-2004): incidence, clinical settings, and visual acuity outcomes after treatment. Am J Ophthalmol 2005;139:983-7.

18. Quiroz Y, Johnson RJ, Rodríguez-Iturbe B. The role of T cells in the pathogenesis of primary hypertension. Nephrol Dial Transplant 2012;27 Suppl 4:iv2-5.

19. Takeichi N, Suzuki K, Okayasu T, Kobayashi H. Immunological depression in spontaneously hypertensive rats. Clin Exp Immunol 1980;40:120-6.

20. Kato S, Chmielewski M, Honda H, Pecoits-Filho R, Matsuo S, Yu- zawa Y, et al. Aspects of immune dysfunction in end-stage renal disease. Clin J Am Soc Nephrol 2008;3:1526-33.

21. Health Insurance Review and Assessment Service. Hospital list [accessed on 2017 October 19]. Available at: https://www.hira. or.kr/rd/hosp/getHospList.do.

22. Norregaard JC, Thoning H, Bernth-Petersen P, Andersen TF, Javitt JC, Anderson GF. Risk of endophthalmitis after cataract extraction: results from the International Cataract Surgery Outcomes study. Br J Ophthalmol 1997;81:102-6.

23. Desai P. The national cataract surgery survey: II. Clinical outcomes. Eye (Lond) 1993;7(Pt 4):489-94.

24. Lundström M, Brege KG, Florén I, Lundh B, Stenevi U, Thorburn W. Postoperative aphakia in modern cataract surgery: part 2: detailed analysis of the cause of aphakia and the visual outcome. J Cataract Refract Surg 2004;30:2111-5.

25. Al Mahmood AM, Al-Swailem SA, Behrens A. Clear corneal incision in cataract surgery. Middle East Afr J Ophthalmol 2014;21:25-31.

26. Taban M, Behrens A, Newcomb RL, Nobe MY, Saedi G, Sweet PM, et al. Acute endophthalmitis following cataract surgery: a systematic review of the literature. Arch Ophthalmol 2005;123:613-20.

27. Lertsumitkul S, Myers PC, O'Rourke MT, Chandra J. Endophthalmitis in the western Sydney region: a case-control study. Clin Exp Ophthalmol 2001;29:400-5.

28. Nagaki Y, Hayasaka S, Kadoi C, Matsumoto M, Yanagisawa S, Watanabe $\mathrm{K}$, et al. Bacterial endophthalmitis after small-incision cataract surgery. Effect of incision placement and intraocular lens type. J Cataract Refract Surg 2003;29:20-6.

29. Matossian C, Makari S, Potvin R. Cataract surgery and methods of wound closure: a review. Clin Ophthalmol 2015;9:921-8.

30. Masket S, Hovanesian JA, Levenson J, Tyson F, Flynn W, Endl M, et al. Hydrogel sealant versus sutures to prevent fluid egress after cataract surgery. J Cataract Refract Surg 2014;40:2057-66.

31. Lee BJ, Smith SD, Jeng BH. Suture-related corneal infections after clear corneal cataract surgery. J Cataract Refract Surg 2009;35: 939-42.

32. Thoms SS, Musch DC, Soong HK. Postoperative endophthalmitis associated with sutured versus unsutured clear corneal cataract incisions. Br J Ophthalmol 2007;91:728-30.

33. Li J, Morlet N, Semmens J, Gavin A, Ng J; EPSWA Team. Coding accuracy for endophthalmitis diagnosis and cataract procedures in Western Australia. The Endophthalmitis Population Study of Western Australia (EPSWA): second report. Ophthalmic Epidemiol 2003;10:133-45.

34. Bainbridge JW, Teimory M, Tabandeh H, Kirwan JF, Dalton R, Reid F, et al. Intraocular lens implants and risk of endophthalmitis. Br J Ophthalmol 1998;82:1312-5. 